\title{
A pilot study of varicella zoster infection among patients with fever and rash in a tertiary care centre
}

\author{
Siddhartha Ojah", Ramya Barani, Padma Srikanth \\ From 2nd International Science Symposium on HIV and Infectious Diseases (HIV SCIENCE 2014) \\ Chennai, India. 30 January - 1 February 2014
}

\section{Background}

Varicella zoster virus (VZV) causes mild self limiting illness in children. Older children and adults may present with atypical manifestations. At present VZV vaccine is not included in national immunization schedule. The study was undertaken to determine the presence of VZV infection in patients with acute febrile illness with rash.

\section{Methods}

Blood samples were collected from patients $(n=36)$ with acute febrile illness with rash in a tertiary care hospital. IgM ELISA was performed according to manufacturer's instructions (IBL International, Germany). Kit standards were used to obtain a standard curve. The results of the samples were interpreted from the standard curve.

\section{Results}

All enrolled patients had fever with rash without evidence of vesicles. Majority, $(\mathrm{n}=29)$ were adults and 18 were male. Of the $14(38.9 \%)$ that were positive by IgM ELISA for VZV, 5 (35.7\%) belonged to the age group of 19-30 years, $4(28.5 \%)$ were $<18$ years and $2(14.3 \%)$ in age group 51-60 years. All patients had normal platelet count except 9 , who had mildly deranged platelet count $(>1.5$ to $<2$ lakh /cumm). All sera that were tested were negative for Dengue NS1 antigen, IgM and IgG antibody capture ELISA (Panbio, Australia).

\section{Conclusion}

VZV may present with atypical manifestation. Non progression of rash to vesicle may warrant testing for VZV

\footnotetext{
* Correspondence: siddhartha.ojah@gmail.com

Department of Microbiology, Sri Ramachandra Medical College and Research Institute, Sri Ramachandra University, Porur, Chennai, India
}

and other viruses in the absence of positive Dengue serology.

Published: 27 May 2014

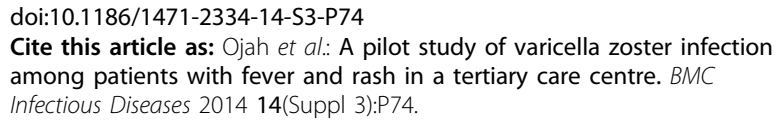

Cite this article as: Ojah et al:: A pilot study of varicella zoster infection among patients with fever and rash in a tertiary care centre. BMC Infectious Diseases 2014 14(Suppl 3):P74.

Submit your next manuscript to BioMed Central and take full advantage of:

- Convenient online submission

- Thorough peer review

- No space constraints or color figure charges

- Immediate publication on acceptance

- Inclusion in PubMed, CAS, Scopus and Google Scholar

- Research which is freely available for redistribution

\section{() Biomed Central}

